\title{
Hidden Waste Factors in LEAN Management: Towards Improved Shop-floor Communication and Management
}

\author{
Anna Nilsson, Trine Terese Eide Brobak, Nikolaj Deleuran Jørgensen, Mette Knak Larsen, \\ Rasmus Davids Damhus, John Bang Mathiasen and Torben Tambo \\ Department of Business Development and Technology, Aarhus University, Herning, \\ Denmark \\ annanilsson7200@hotmail.com \\ trinetb@hotmail.com \\ nikolajdeleuranjorgensen@gmail.com \\ mett9048@gmail.com \\ dammer94@hotmail.com \\ johnbm@btech.au.dk \\ torbento@btech.au.dk \\ DOI: 10.34190/MLG.19.015
}

Abstract: Shop-floor management (SFM) following LEAN thinking employs predominantly analogue whiteboards for daily communication between floor management and floor employees. Whiteboards as communication platforms are integrated with daily stand-up meetings. The purpose of this paper is a comparative study between analogue and digital approaches with the hypothesis that continued use of analogue LEAN boards leads to (excessive) waste occurrence compared to going digital. This paper is based on two qualitative, interpretivist case studies of manufacturing organisations. Data include styles of management data visualisations, observations of LEAN board meetings, and process analysis of data management. The communication processes as a core activity of the SFM are studied from a lens of value stream mapping (VSM) for communication and also management style and impact. Key findings are that waste occurs when staying loyal to analogue LEAN boards, as several of the processes can be limited or even eliminated by rightfully utilising digital LEAN boards. Given the higher effectiveness of digital approaches, this paper concludes that the dogma of continuous use of analogue LEAN boards must be discussed as a key factor in modernising LEAN SFM and the outreach to the employees involved. This paper's originality comes from LEAN-based SFM as increasingly founded around daily stand-ups and styles of LEAN boards, alongside industrial megatrends of digitisation. This paper adds to the discussion of approaches for optimal SFM and the relationship among communication media, management paradigm, and LEAN waste factors. The case companies are at different levels of maturity of LEAN; however, the fundamental management philosophy is the same and largely points to the same results. When it comes to digital LEAN boards, this paper suggests opportunities to reduce waste and have a transparent knowledge base, decision-making foundation, and conscious organisation of operational management.

Keywords: LEAN production, waste, Industry 4.0, LEAN management boards, digitisation in industry

\section{Introduction}

Ohno is largely accredited for having developed the Toyota Production System (TPS) in the post-war era of the Japanese industrial boom (Tezel, Koskela, and Tzortzopoulos, 2009). The TPS combines Western industrialism with Japanese tradition and forms the foundation of modern-day LEAN management principles (Alves, DinisCarvalho, and Sousa, 2012). Within the TPS, continuous improvement boards were the value drivers for the engagement of employees together with the visual follow-up of the key performance indicators (KPI) (Meudt, Metternich, and Abele, 2017). The primary goal of these boards was to engage the employees, to be creative, and to contribute with their knowledge to improve the process. As of 2019, digitisation of industrial production is the leading strategic priority in most industries, with Industry 4.0 as a frontrunner trend (Brenner and Hummel, 2017; Gruber, 2013; Yin, Stecke, and Li, 2017).

Continuous improvement boards are still a vital part of the visualisation process. Today, they are often seen as whiteboards with coloured markers and magnets holding on to excel charts printed from the computers of the LEAN manager. In a survey, Clausen, Mathiasen, and Nielsen (2018) established that most companies are sticking with analogue LEAN boards. Some use both analogue and digital boards, while a clear minority exploits only the possibilities of digital LEAN boards (see Figure 1).

The purpose of this paper is to determine how the application of analogue LEAN boards affects waste occurrence at the shop-floor management (SFM) level, compared to having digital LEAN boards. Does unnecessary waste exist with analogue LEAN boards compared to digital LEAN boards, potentially continuing 
to produce unnecessary waste? It is not the first time core principles of LEAN have been challenged. Goldsby, Griffis, and Roath (2006) found that some results from the agile and leagile approaches aligned better with the LEAN philosophy than the LEAN approach itself.

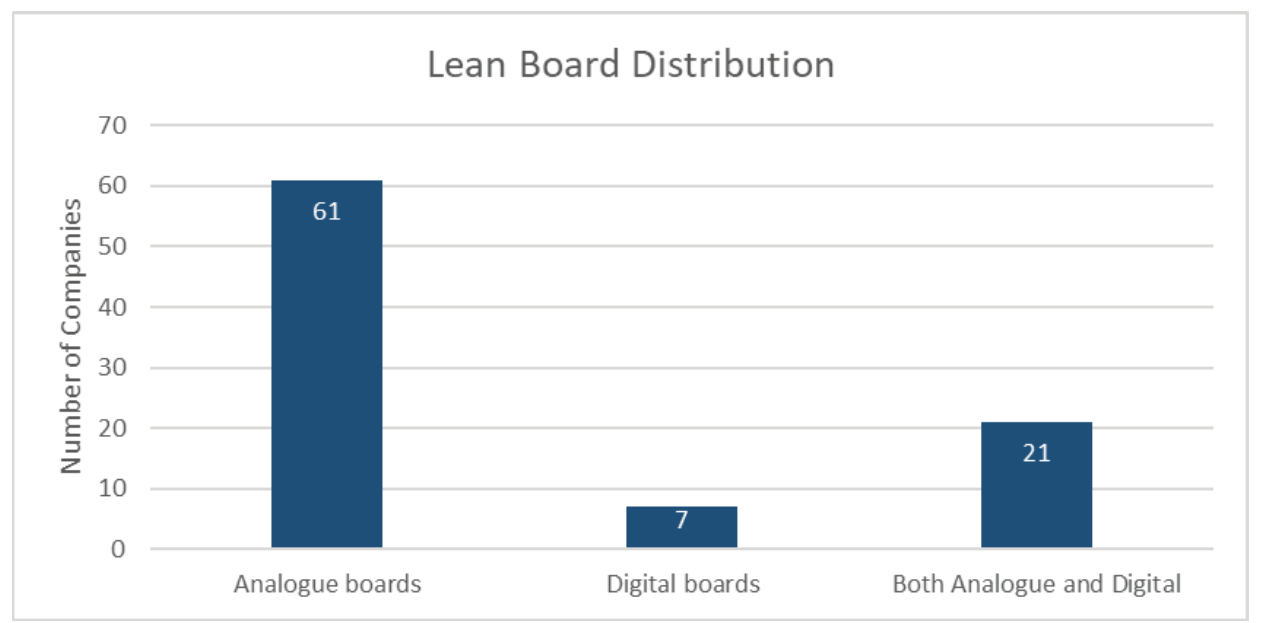

Figure 1: LEAN board distribution (Clausen, Mathiasen, and Nielsen, 2018)

The research will focus on the activities performed prior to a LEAN board meeting, the activities performed during the LEAN board meeting, and the knowledge transfer afterwards to compare the two different processes. This means that the factors taken into consideration will be data retrieval, data visualisation, LEAN board meeting, and data archiving. The focus will be on SFM and the utilisation of LEAN boards at this level.

The conclusion is if continued use of analogue LEAN boards is a hidden waste factor in the current LEAN setup compared to digital LEAN boards by investigating present waste types with manual data handling and potential waste elimination from digital LEAN boards. This leads to the problem formulation: How is the application of analogue LEAN boards affecting the waste occurrence at the SFM level compared to having digital LEAN boards?

\section{Literature review}

\subsection{LEAN}

LEAN is the dominating approach for improving operational productivity and organisational performance (Tay and Low, 2017). LEAN is rooted in TPS. Shah and Ward (2007) investigated the early definitions of the concepts in the original Japanese literature. The focus of this article is defining elements of the LEAN philosophy, specifically regarding waste, recognised as muda in the original literature (Alves, Dinis-Carvalho, and Sousa, 2012; Maison-Jones, Naylor, and Towill, 2000).

In LEAN, the elimination of seven non-value adding (NVA) waste types is a key objective. These are: transportation, defects, overproduction, waiting, inventory, motion, and processing (Womack and Jones, 1996). Ohno first described the seven types of waste used in LEAN thinking, but multiple researchers like Suzaki (1993) and Womack and Jones (1996) have proposed an eighth waste type. Womack and Jones (1996) proclaimed the eighth waste type to be the underutilisation of people and their creative input for improvements. Another definition is argued by Suzaki (1993): “Not utilizing people's talent or underutilizing people's skills and capabilities". Womack and Jones (1996) top based on their statement, "Muda is everywhere".

Research has found the original seven waste types insufficient to describe the types of waste that can occur in an industrial environment (Sutrisno et al., 2018). Sutrisno et al. (2018) suggest 14 types of waste to accommodate the scenarios companies are exposed to in the 21st century. These seven new types of waste are to be seen as an addition to the original seven waste types. The 14th type of waste is relevant regarding the topic of digitisation, as it revolves around: digital waste in forms of duplicating efforts, overdesigning, excessive overhead, poor planning, poor measurement, and poor coordination (Sutrisno et al., 2018). 
Distinctive requirements on support of stakeholders' engagement, effort, information transparency and credibility can contribute to avoidance of digitally induced waste in SFM (Brenner and Hummel, 2017; Hertle et al. 2015).

Ohno (1978) argues elimination of waste is essential for the organisational success. Distinction needs to be made between necessary and unnecessary waste, in which the goal should be the elimination of unnecessary waste and a reduction of the necessary waste (Gibbons et al., 2012). Monden (1993) states three main types of activities: non-value adding (NVA), necessary but non-value adding (NNVA), and value-adding (VA) activities.

- $\quad$ NVA activities are categorised as pure waste, and this includes the activities LEAN as a philosophy wants to eliminate completely (Hines and Rich, 1997). NVA activities include waiting time, double handling of products, unnecessary transportation of materials, etc.

- $\quad$ NNVA activities can be defined as wasteful and non-optimised operating procedures, but procedures that are necessary for the current operation. These NNVA activities are difficult to convert to VA activities in the short run but are possible to change in the short to long run.

- VA activities add value to a given activity. In a manufacturing environment, VA activities can be represented by sub-assemblies, painting body work, or shaping raw materials.

While on the subject of waste, superfluous work should be mentioned. Superfluous work is often seen as a VA activity, but an NVA activity that is difficult to identify (Ålstrom and Modig, 2012). A way of eliminating these waste factors could be through digitisation.

\subsection{Next generation shop-floor management}

The SFM definition can be expressed as 'activities directed toward maintaining current technological, managerial and operating standards' (Imai, 1986). Workers contribute with their value to the business on the shop floor, and SFM is an important area for the overall corporate performance (Ma et al., 2018). SFM must be understood as a complex process including communication, improvement, relationships, and management at its core (Olivella, Cuatrecasas, and Gavilan, 2008).

Few authors have touched digitisation at the SFM level, and limited literature is available (Meissner et al., 2018), although digitisation of the shop floor is high on corporate agendas (Zhong et al., 2017; Zhuang and Xiong, 2018). Leyendecker and Patrick (2018) define SFM as visible and standardised leadership on the spot, a managerial system divided into four central SFM areas:

1. Standardization and optimization of processes

2. Creating transparency for all stakeholders

3. Culture and organization (presence of executives on the shop floor)

4. Key figures for leading with numbers, data and facts" (Leyendecker and Patrick, 2018).

Leyendecker and Patrick (2018) argue that results are created between SFM and the above-mentioned central areas. The future environment of the shop floor is expected to be more intensive and challenging (Holm, 2018). Holm (2018) argues for a future need for interpersonal and technical competencies of the shop floor workers to be able to keep up productivity and remain competitive. The need for digitisation is highlighted by several authors in the literature (Kadar et al., 2010; Meissner et al., 2018).

Improving and developing the employees' competencies at the SFM level can be done by 'increasing competences through the processes' (Hertle et al., 2015). As a result of pressure from the management, employees need to adapt and acquire new competencies, especially within data interpretation, e.g. KPI understanding. Hertle et al. (2015) argue this shall be done to utilise the employees' full potential, thereby reducing the eighth waste type, non-utilised talent.

Hertle et al.'s (2015) underline the presence of managers and to adaptation to the different areas of a business and to increase their utility development to become higher-performing leaders. This is done by going from 'shop floor supervisors to methodical coaches' (Hertle et al., 2015). The ultimate goal is twofold: to enhance and encourage the operational performance (KPIs) of a company and to execute actions leading to a higher degree of LEAN implementation. These goals are complementary and should support one another.

Manufacturing companies are approaching Industry 4.0, and some have already progressed into Smart Manufacturing (Yin, Stecke, and Li, 2017; Zhong et al., 2017; Zhuang and Xiong, 2018). Digitisation of SFM 
meetings is a subsequent step in achieving results on the shop-floor level. Information and learning across different functions prove a good way to communicate and secure knowledge management in between departments (Fast-Berglund, Harlin, and Åkerman, 2016). Digitisation of the analogue LEAN board promotes a more efficient meeting environment for companies and more so for multiple locations or globalised companies (Fast-Berglund, Harlin, and Åkerman, 2016; Warnhoff and Lareiro, 2019). Perils of this momentum is induction of digital waste, as presented above, which itself hampers innovations due to resistance from management or employees (Clausen et al., 2018).

\section{Methodology}

\subsection{Research methodology and data collection}

The applied research methodology in this article is a combination of case studies from interviews and a literature review. Qualitative research methods have been chosen to explore and understand the differences between the two types of LEAN boards. Two cases are chosen that represent either the analogue or the digital LEAN boards. The cases represent different industries and sizes to increase the generalisability. However, the generalisability is low when choosing only two cases, and it would increase if more cases were part of the research. The cases are listed with their differences in industry and size in Table 1 below.

Table 1: Overview of cases

\begin{tabular}{|l|l|l|}
\hline & Company $X$ - Digital Boards & Company Y - Analogue Boards \\
\hline Industry & Food additives industry & Food industry \\
\hline Employees in Denmark & $\approx \mathbf{1 , 0 0 0}$ employees & $\approx \mathbf{2 5 , 0 0 0}$ employees \\
\hline Yearly turnover & $<\mathbf{5}$ billion DKK & $\mathbf{> 5 0}$ billion DKK \\
\hline
\end{tabular}

Semi-structured interviews were conducted, since it is a useful data collection method to understand opinions, experiences, and processes (Rowley, 2012). The questions concern the data handling processes before and after a board meeting to highlight the different processes between analogue and digital LEAN boards. Semistructured, in-person interviews were chosen to allow the interviewed person to highlight elements beyond the questions asked. An inductive approach was chosen for the research with the aim to explore a theoretical explanation from the data that have been collected and analysed (Saunders, Lewis, and Adrian, 2016).

\subsection{Delimitations}

The primary focus of the research starts from the data retrieval regarding the manufacturing process. The research does not focus on the steps before data retrieval, such as setting up the process for collecting and coding the data. This paper focuses on management at the SFM level, and therefore only the application of LEAN boards. The decision for choosing either of the boards will, for that reason, not be covered in this research. The aim is to illuminate whether waste emerges when choosing the analogue in preference to the alternative digital LEAN boards.

\section{Results}

\subsection{Company Y - Analogue boards}

Data retrieval: The analogue board meetings at Company $Y$ require manual data collection consisting of timeconsuming manual work. For each KPI, the responsible LEAN manager spends approx. 15 minutes on each $\mathrm{KPI}$.

The number of KPIs depends on the projects and current focal areas of attention. It can thus take several hours if several KPIs are needed. The manual collection of the data is complex and time-consuming, as the measurements are done using pen, paper, and stopwatch. The measurement of time spent on a given process takes place manually during production. The LEAN manager attends the production, makes a fixed number of trials to time the process, and notes the results. The average time is then entered into Excel to form a graph.

Data visualisation: The visualisation of the data varies across the departments, but the data are written by hand on a whiteboard or visualised through graphs, which are created in Excel and thereafter printed.

LEAN board meeting: Input or ideas from the employees are manually written in a notebook consisting of notes from past meetings. 
Data archiving: A picture of the board is sometimes taken after the meeting as a record to replace or complement the notes. The handling of the picture is the same procedure as the notes; however, a little extra work transferring the notes into the notebook is needed.

Company $Y$ believes there is a lot of preliminary work that needs to be done before it is possible to convert the analogue LEAN board meaningfully into digital LEAN boards.

\subsection{Company X-Digital boards}

Data retrieval: For the digital board meetings, most of the quantitative data is collected automatically through an ERP system. Furthermore, there are also some data, mostly qualitative, that need to be updated manually. The representative acknowledges the collection to be simple, and the time spent on a daily basis does not exceed 15 minutes.

Data visualisation: The visualisation of the LEAN board meeting was created by internal resources in the company's internal information system, which means the digital board is not from external sources, i.e., Trello and iObeya. The data are visualised using graphs, tables, or text, and the creation of these are included in the 15 minutes mentioned above.

LEAN board meeting: New proposals and feedback are transferred to the board during the meeting, which means there is no data handling when the meeting is done. A keyboard is connected to the system for that purpose, and the team can add or change any new items.

Data archiving: The information in this step is automatically transferred and thus a non-manual task, meaning no time spent.

The company has experienced a positive effect since implementing digital LEAN boards. It has become easier to make changes, feedback from employees has increased, and the process is more manageable, as everything is collected and easy to find. The operators have been trained to use all the facilities in the digital programme and are encouraged to utilise the facilities themselves. Thereby, the overall level of confidence remains high in using digital LEAN boards, and changes can be made without overloading the team leader.

\subsection{Comparative approach}

The overall comparison of the two cases above is illustrated in Table 2 below.

Table 2: Case comparison

\begin{tabular}{|c|c|c|c|c|}
\hline & \multicolumn{2}{|l|}{ Company X - Digital Boards } & \multicolumn{2}{|l|}{ Company Y - Analogue Boards } \\
\hline & & Time spent: & & Time spent: \\
\hline Data Retrieval & Automatic data collection & & $\begin{array}{l}\text { Manual data collection, using } \\
\text { stopwatch }\end{array}$ & $\begin{array}{l}15 \text { minutes per } \\
\mathrm{KPI}\end{array}$ \\
\hline $\begin{array}{l}\text { Data } \\
\text { Visualization }\end{array}$ & $\begin{array}{l}\text { Graphs are automatically } \\
\text { updated with few } \\
\text { modifications }\end{array}$ & $>15$ minutes & $\begin{array}{l}\text { Qualitative data is handwritten } \\
\text { on whiteboard. } \\
\text { Graphs are created in Excel and } \\
\text { printed }\end{array}$ & $\begin{array}{l}\text { Several hours } \\
\text { per week }\end{array}$ \\
\hline $\begin{array}{l}\text { LEAN Board } \\
\text { Meeting }\end{array}$ & $\begin{array}{l}\text { Inputs are typed into the } \\
\text { system during the meeting }\end{array}$ & Varies & $\begin{array}{l}\text { Inputs are written on paper and } \\
\text { put in a folder on the board }\end{array}$ & Varies \\
\hline Data Archives & $\begin{array}{l}\text { No archiving as inputs are } \\
\text { typed directly into the } \\
\text { system during the meeting }\end{array}$ & 0 minutes & $\begin{array}{l}\text { Notes are handwritten } \\
\text { A picture is taken of the board }\end{array}$ & $\begin{array}{l}10 \text { minutes per } \\
\text { day }\end{array}$ \\
\hline
\end{tabular}

It was recorded that Company $\mathrm{X}$ is creating graphs and tables in approximately 15 minutes. Company $\mathrm{Y}$ must spend extra time to analyse its data before being able to create the graphs, which also must be printed before the meeting. This is a waste factor.

The main difference between the two case studies is that Company $X$ archives the data in its IT system. Compared to Company $Y$, the archiving is isolated to the phones and notebook of the respective LEAN manager. Company $Y$ does not obtain and accumulate data and hence does not have historical data. Each time 
the company finds an area to investigate and further optimise, it starts from scratch and does not have a reference point.

\section{Discussion}

Data retrieval. Poor measurement is a subtype of waste relating to the 14th waste type, digital waste (Sutrisno et al., 2018). Company $Y$ collects data through a manual and time-consuming process with stopwatch, pen, and paper. Company $X$ utilises business intelligence tools to retrieve the data, which means the approach of Company $Y$ can be argued as an NNVA activity. The reason why this activity is an NNVA activity is because it could have been removed if the company had the digital alternative. This manual data collection method could be seen as the eighth waste type, which is non-utilised talent. This waste type is present as these employees could be allocated to more VA tasks by utilising digital LEAN boards. There are digital alternatives to this process, which could reduce this waste type at Company Y. Below a collection of statements and impressions from direct stakeholders are recording from the factories:

- Blue collar (manual board): "The supervisor is saying a lot, but we can't find we he said a month ago as they change the board documents all the time. Sometimes we don't believe in him."

- Supervisor (semi-digital board): "Things are just easier as data is available all the time." "I save a lot of time by having the staff information automatically generated."

- "Sometimes I fear that I get redundant or fail to assure the staff know my intentions."

- Planner (manual board): "It is annoying to print and put documents on the board, when things are easily available on the computer."

- Blue collar (semi-digital board): "It is nice to be able to see management information also when I have been absent for the meetings. I can also see some of it on then computer in the production."

Data visualisation. The visualisation process at Company $Y$ requires activities before, during, and after visualising the data. Compared to Company $X$, it eliminated the last two activities, since the company is not editing and printing the visualisations. These additional activities that Company $Y$ performs can be seen as the waste type of overprocessing when comparing the activities to a digital alternative. It can also be seen as digital waste as proposed by Sutrisno et al. (2018), since there is an alternative available for the activities. The digital waste refers to the duplication efforts that these extra steps create.

Data archiving. Digital waste can also be seen in the way Company $Y$ starts from scratch each time it finds a new area to investigate for future optimisation, since it has no reference point from its own previous experiences. This means Company $Y$ is doing the same thing over and over again. It can be viewed as an NNVA action because it is necessary to do at the moment, but more efficient alternatives do exist. Furthermore, the duplicating effort is part of the digital waste.

The waste type regarding processing can also be seen in the number of steps Company $Y$ uses compared to Company X's when handling data. The activities move from NNVA to VA activities when changing to digital LEAN boards.

Digital vs. analogue LEAN boards. The continued use of analogue LEAN boards means that the non-utilisation of data and non-archiving of the data reduce the transparency of the company by creating knowledge islands. When only having the data in a notebook and pictures on a single phone, Company $Y$ is vulnerable, as the LEAN manager becomes irreplaceable.

Decision making on analogue vs digital approaches to communication, visualisation, and management is complex. There are many good arguments for digital approaches, but why stick to analogue communication? LEAN board meetings seem to have a lot of ritual elements attached. The meetings represent the main face to face interaction between management and staff. Management expects staff to understand priorities and establish a sense of urgency. Management is positioned through meetings that are mostly one-way communication. The manager may be seeking admiration, social respect, dominance, and assurance of his/her sphere of power.

Staff can be puzzled about their roles in meetings, as they are minimally involved, share limited priorities with the management, might not understand the exact meaning of terms applied, and see KPIs coming and going with modest influence on selection, definition, measurement, strategic adherence, and closing down on 
specific KPIs. The staff join the meetings to avoid blame, have a break and coffee, listen to potential changes affecting them, file complaints, and many other issues with divergence from the core and essential purpose of LEAN board meetings.

The purpose of the meetings is continuous improvement. Many formal, practical, social, and ethnological agendas can co-exist below the agenda. Digital vs analogue communication is seemingly an indirect part of this, although certain rituals around the analogue approaches seem to be the 'power lifeline' of the manager rather than of importance to staff. Digital LEAN board meetings, as in our observations from Company X, seem to promote more 'sterile' communication. For example, archiving providing transparency in turn makes communication less disputable. The personal appearance of analogue meetings underlines the esteem and role of the individual, whereas the digital communication is far more cleansed from underlying agendas. This can be summarised in a discussion of the readiness and feasibility of either approach. The company with standardised processes and relatively clear roles distributed between management and staff will have more benefits of digital approaches than companies with a low level of standardisation, process stability, organisational statics, and probably also market-related issues in respect to batch size, customisation, professionalism, and technological uncertainty. This argument can then be reversed to claim that companies can increase stability and process assurance by switching to digital LEAN boards.

\section{Conclusions}

The problem formulation for this research was: How is the application of analogue LEAN boards affecting the waste occurrence at the SFM level compared to having digital LEAN boards? Given that a majority of data used in analogue LEAN boards are produced out of digital platforms, there is a clear element of digital waste in not having and using digital LEAN boards. The waste was identified in the data retrieval, data visualisation, and data archiving when having analogue compared to digital LEAN boards. Our discussion highlights that no matter how rational digital approaches are, there might be issues in companies where analogue LEAN boards are preferred. Issues can be divided into (1) a lack of stability of business processes and (2) factory managers' personal preferences for interpersonal management styles. In any case of maturing, both issues might be problematic for the company's further growth.

When comparing analogue and digital LEAN boards, some of the activities are seen as NNVA and timeconsuming. When comparing analogue and digital LEAN boards, NNVA activities appear in the analogue LEAN boards. They are necessary for the current process, but compared to the digital alternative, they are NVA. The overall conclusion is that the research based on the two case studies has shown the existence of waste based on the waste types suggested by Sutrisno (2018), where primarily the 14th waste type, digital waste, is present. This links the $14^{\text {th }}$ waste type to business process stability, objective vs subjective management styles in SFM, and the overall level of digital readiness and maturity.

\section{References}

Ålstrom, P. and Modig, N. (2012) This is Lean: Resolving The Efficiency Paradox, Rheologica Publishing, Halmstad.

Alves, A.C., Dinis-Carvalho, J. and Sousa, R.M. (2012) 'Lean production as promoter of thinkers to achieve companies' agility", The Learning Organization, Vol. 19, No. 3, pp 219-237.

Brenner, B. and Hummel, V. (2017) "Digital twin as enabler for an innovative digital shopfloor management system", Procedia Manufacturing, Vol. 9, pp 198-205.

Clausen, P., Mathiasen, J.B. and Nielsen, J.S. (2018) Barriers and Enablers for Digitizing Shop Floor Management Boards, Department of Business Development and Technology, Herning.

Fast-Berglund, A., Harlin, U. and Åkerman, M. (2016) "Digitalisation of meetings: from white-boards to smart-boards", Procedia CIRP, Vol. 41, pp 1125-1130.

Gibbons, P.M., Kennedy, C., Burgess, S.C. and Godfrey, P. (2012) "The development of a lean resource mapping framework: introducing an 8th waste", International Journal of Lean Six Sigma, Vol. 3, No. 1, pp 4-27.

Goldsby, T.J., Griffis, S.E. and Roath, A. (2006) "Modeling lean, agile and leagile supply chain strategies", Journal of Business Logistics, Vol. 27, No. 1, pp 57-80.

Gruber, F.E. (2013) "Industry 4.0: A best practice project of the automotive industry", in IFIP International Conference on Digital Product and Process Development Systems, pp 36-40, Springer, Berlin.

Hertle, C., Metternich, J., Siedelhofer, C. and Abele, E. (2015) "The next generation shop floor management: how to continuously develop competencies in manufacturing environments", The 23rd International Conference on Production Research.

Hines, P. and Rich, N. (1997) "The seven value stream mapping tools", International Journal of Operations \& Production Management, Vol. 17, No. 1, pp 46-64. 
Holm, M. (2018) "The future shop-floor operators, demands, requirements and interpretations", Journal of Manufacturing Systems, Vol. 47, pp 35-42.

Imai, M. (1986) Kaizen: The Key to Japan's Competitive Success, McGraw-Hill, New York.

Kádár, B., Lengyel, A., Monostori, L., Suginishi, Y., Pfeiffer, A. and Nonaka, Y. (2010). “Enhanced control of complex production structures by tight coupling of the digital and the physical worlds", CIRP annals, Vol. 59, No. 1, pp 437-440.

Leyendecker, B. and Patrick, P. (2018) "Definition und Nutzen von SFM", in Shopfloor Management Führung am Ort des Geschehens, pp 11-17, Carl Hanser Verlag, Berlin.

Ma, J., Jiao, F., Lau, C.K. and Lin, Z. (2018) "The relationships between shop floor management and QCCs to support Kaizen", International Journal of Quality \& Reliability Management, Vol. 35, No. 9, pp 1941-1955.

Maison-Jones, R., Naylor, B. and Towill, D. (2000) "Lean, agile or leagile? Matching your supply chain to your marketplace", International Journal of Production Research, Vol. 38, No. 17, pp 4061-4070.

Meissner, A., Muller, M., Hermann, A. and Metternich, J. (2018) “Digitisation as a catalyst for lean production: A learning factory approach for digital shop floor management", Procedia Manufacturing, Vol. 23, pp 81-86.

Meudt, T., Metternich, J. and Abele, E. (2017) "Value stream mapping 4.0: Holistic examination of value stream and information logistics in production", CIRP Annals, Vol. 66, No. 1, pp 413-416.

Monden, Y. (1993) Toyota Production System: An Integrated Approach to Just-In-Time, Industrial Engineering and Management Press, Norecross, GA.

Ohno, T. (1978) Toyota Production System: Beyond Large-Scale Production. 1st ed., www.diamond.co.jp/Press, Tokyo.

Olivella, J., Cuatrecasas, L. and Gavilan, N. (2008) "Work organisation practices for lean production", Journal of Manufacturing Technology Management, Vol. 19, No. 7, pp 798-811.

Rowley, J. (2012) “Conducting research interviews", Management Research Review, Vol. 35, No. 3/4, pp 260-271.

Saunders, M., Lewis, P. and Adrian, T. (2016) Research Methods for Business Students, Pearson, Harlow.

Shah, R. and Ward, P. (2007) "Defining and developing measures of lean production", Operations Management, Vol. 25, pp 785-805.

Sutrisno, A., Vanany, I., Gunawan, I. and Asjad, M. (2018) "Lean waste classification model to support the sustainable operational practice", IOP Conference Series: Materials Science and Engineering.

Suzaki, K. (1993) The New Shop Floor Management: Empowering People for Continuous Improvement, The Free Press, New York.

Tay, H.L. and Low, S. (2017) "Digitisation of learning resources in a HEl: a lean management perspective", International Journal of Productivity and Performance Management, Vol. 66, No. 5, pp 680-694.

Tezel, B.A., Koskela, L.J. and Tzortzopoulos, P. (2009) The Functions of Visual Management, University of Salford.

Warnhoff, K. and Lareiro, P. (2019) "Skill development on the shop floor-heading to a digital divide?", Weizenbaum Conference, pp 1-10.

Womack, J.P. and Jones, D. (1996) Lean Thinking: Banish Waste and Create Wealth in Your Corporation, Simon and Schuster, London.

Yin, Y., Stecke, K.E. and Li, D. (2017) "The evolution of production systems from Industry 2.0 through Industry 4.0", International Journal of Production Research, Vol. 24, pp 848-861.

Zhong, R., Xu, C., Chen, C. and Huang, G. (2017) "Big data analytics for physical Internet-based intelligent manufacturing shop floors", International Journal of Production Research, Vol. 55, No. 9, pp 2610-2621.

Zhuang, C., Liu, J. and Xiong, H. (2018) "Digital twin-based smart production management and control framework for the complex product assembly shop-floor", The International Journal of Advanced Manufacturing Technology, Vol. 96, No. 1-4, pp 1149-1163. 